\title{
EDITORIAL
}

\section{Appreciation and future prospects}

incere thanks to Harold Merskey, past EditorSin-Chief, and Robert Kalina, Publisher of Pulsus Group Inc, for their kind welcome in the most recent issue of Pain Research $\mathcal{E}$ Management. I embrace the role of Editor-in-Chief with enthusiasm because it offers opportunities to participate further in the development of pain research and management and to advance the objectives of the Canadian Pain Society. Publication of ideas and findings concerning the nature and control of pain, whether in print, electronic media or oral dissemination of information, represents the primary means whereby scientists and professionals in this important field share ideas. Journals communicate the best and it is a privilege to foster this process.

Pain Research $\mathcal{E}$ Management has become a remarkably successful journal thanks to Harold Merskey's leadership, the contributors to its editorial pages, the distinguished group of Associate Editors, International Consultants, and reviewers who shape and nurture the Journal, the efforts of Pulsus and the business community that supports the Journal. Its circulation is approximately 15,800 , indicating a far-reaching and penetrating impact on science and practice in Canada and the international community. All readers can find material of importance to them in every issue. The Journal publishes incisive empirical reports, research and clinical syntheses, guidelines and commentaries across the broad domains of science and practice, and it enjoys broad recognition among journals in the field, as reflected by indexing in Index Medicus/MEDLINE, EMBASE/Excerpta Medica and PsycINFO. In part, the success of the Journal reflects the long history of exemplary contributions and leadership provided by Canadians in the international community of scientists and professionals working on the challenges of understanding and controlling pain. A great deal has been accomplished over the first 12 years of Pain Research $\mathcal{B}$ Management and I welcome the opportunity to further develop an already fully functioning and highly effective journal.
The Journal is successful in part because it accepts diverse submissions, ranging among empirical and theoretical papers, review articles, guidelines, commentaries, special series, letters and book reviews. As well, occasional lively items of humour, poetry and whimsy, illustrating the realities of pain, will continue to be welcomed. Contributions appear from across the multiple disciplines that address pain, reflecting all approaches from the basic and clinical sciences to social and cultural determinants of health, population health, and health service delivery and policy.

I have long felt that the name of the journal, Pain Research $\mathcal{E}$ Management, signified special opportunities to bridge these domains. They are interdependent, and advances in each support the others. Current enthusiasm for supporting knowledge translation or knowledge transfer signifies the importance of basic scientists spelling out the implications of their discoveries for the health of people suffering from pain. Evidence-based and systematic review papers bridging research and practice will be most welcome.

One immediate change will be the move to increase electronic services. For some time, readers have had available opportunities to electronically access abstracts, and full text papers have been available online to Canadian Pain Society members. In the near future, we will introduce electronic processing of manuscripts, beginning with accepting on-line submissions, and continuing through acknowledgement, distribution to and responses by editorial reviewers, and feedback to authors. This will speed the process and make the editorial review process substantially more efficient.

In summary, I look forward to working with that broad community with a sincere interest in pain research and management to further develop this journal as a means of communicating advances in science and practice. Keep those manuscripts coming!

Kenneth D Craig PhD 


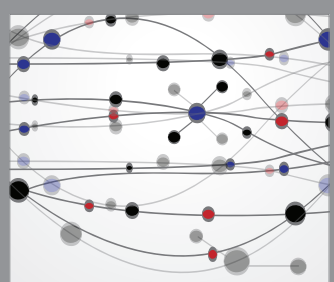

The Scientific World Journal
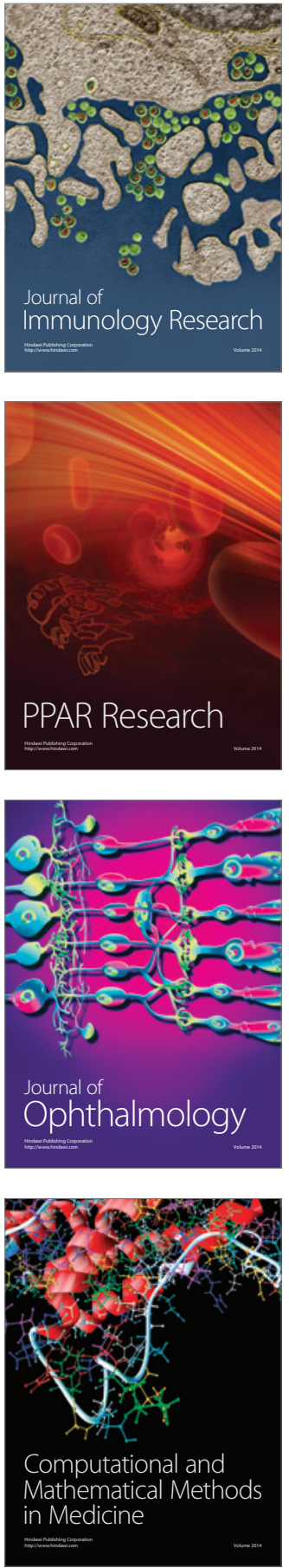

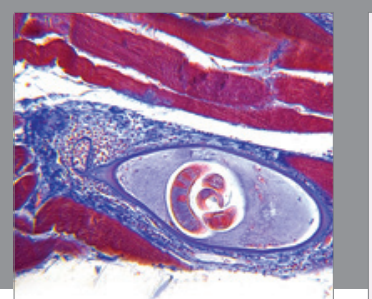

Gastroenterology Research and Practice

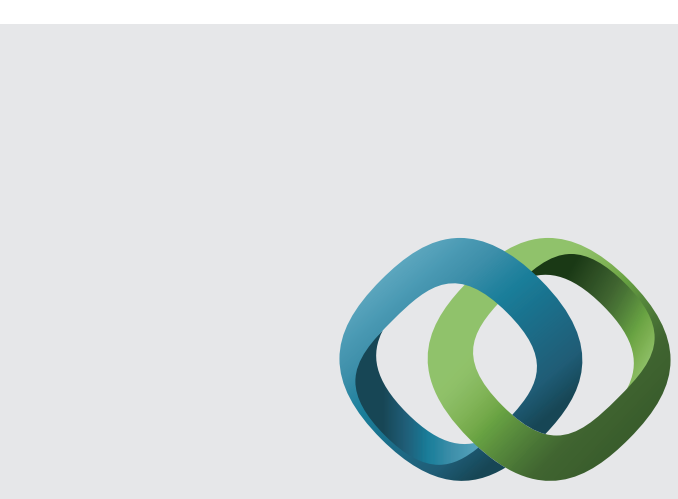

\section{Hindawi}

Submit your manuscripts at

http://www.hindawi.com
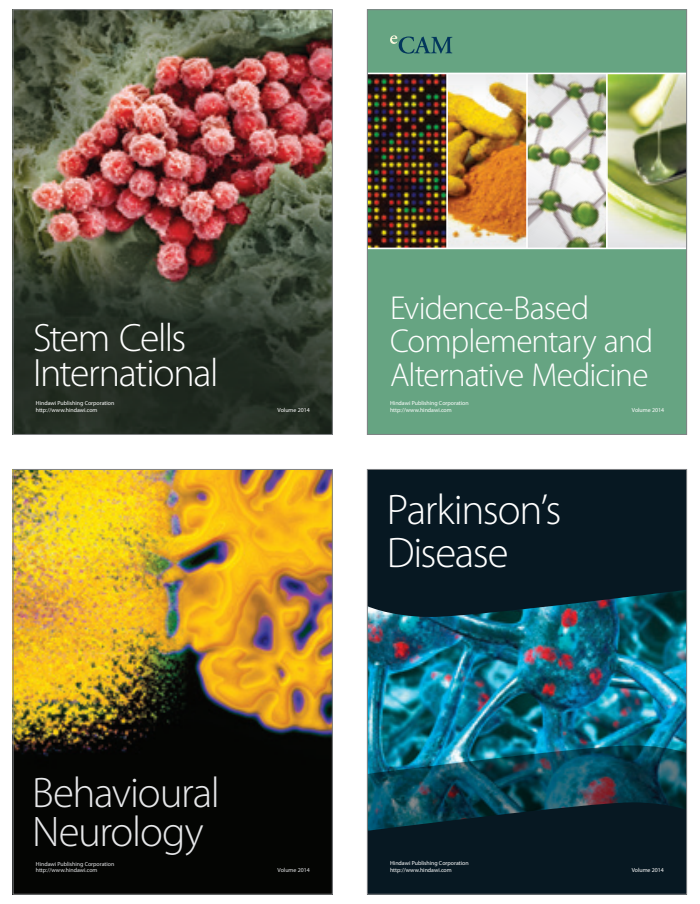
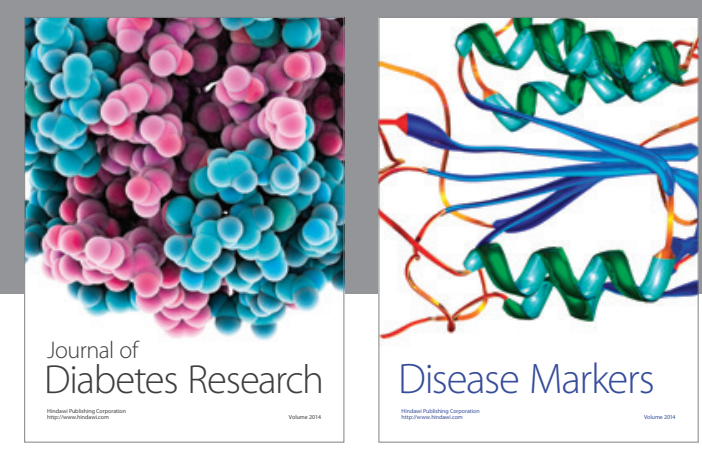

Disease Markers
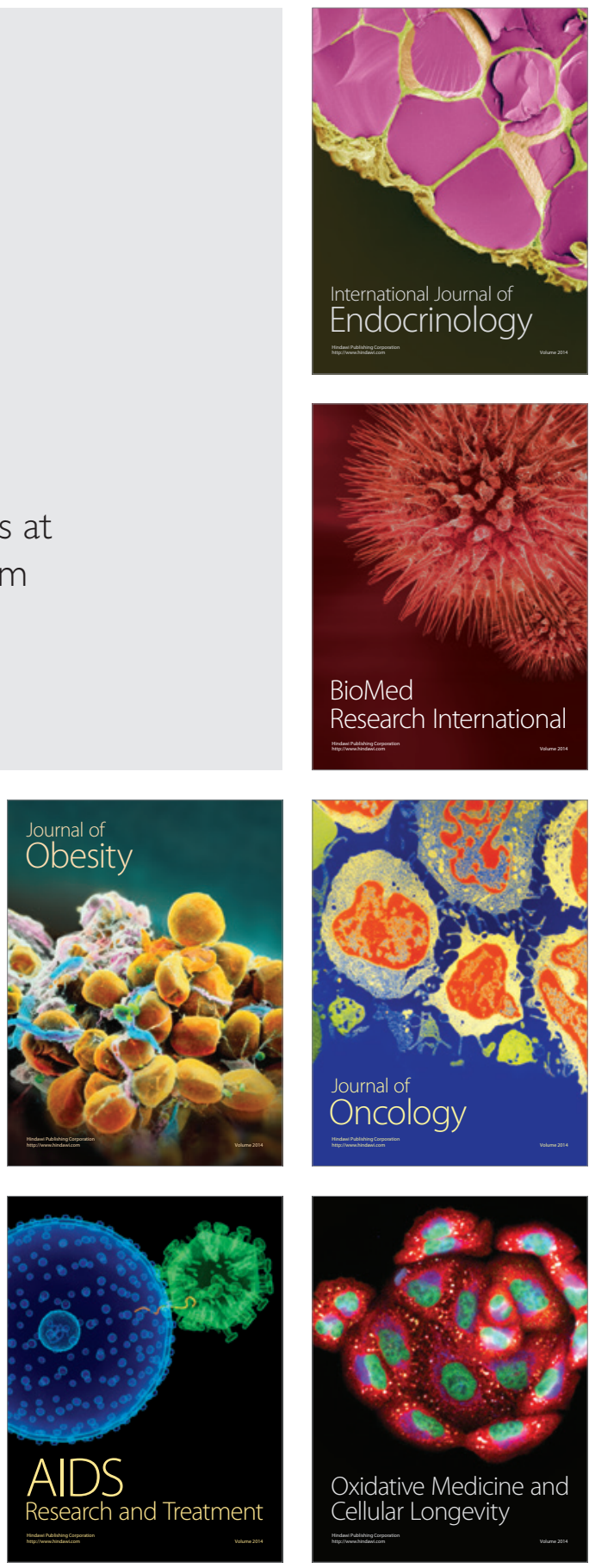